\title{
Generalized Autoregressive Conditional Heteroskedastic Model to Examine Silver Price Volatility and Its Macroeconomic Determinant in Ethiopia Market
}

\author{
Amare Wubishet Ayele $\mathbb{D}^{\mathrm{D}}{ }^{1}$ Emmanuel Gabreyohannes $\mathbb{D}^{\mathrm{D}}{ }^{2}$ and Hayimro Edmealem ${ }^{1}$ \\ ${ }^{1}$ Department of Statistics, College of Natural and Computational Science, Debre Markos University, Debre Markos, Ethiopia \\ ${ }^{2}$ Mathematics and Statistics Department, Ethiopian Civil Service University, Addis Ababa, Ethiopia \\ Correspondence should be addressed to Amare Wubishet Ayele; amarewubishet21@gmail.com
}

Received 12 February 2020; Revised 3 April 2020; Accepted 24 April 2020; Published 25 May 2020

Academic Editor: Aera Thavaneswaran

Copyright (C) 2020 Amare Wubishet Ayele et al. This is an open access article distributed under the Creative Commons Attribution License, which permits unrestricted use, distribution, and reproduction in any medium, provided the original work is properly cited.

\begin{abstract}
Like most commodities, the price of silver is driven by supply and demand speculation, which makes the price of silver notoriously volatile due to the smaller market, lower market liquidity, and fluctuations in demand between industrial and store value use. The concern of this article was to model and forecast the silver price volatility dynamics on the Ethiopian market using GARCH family models using data from January 1998 to January 2014. The price return series of silver shows the characteristics of financial time series such as leptokurtic distributions and thus can suitably be modeled using GARCH family models. An empirical investigation was conducted to model price volatility using GARCH family models. Among the GARCH family models considered in this study, ARMA $(1,3)$-EGARCH $(3,2)$ model with the normal distributional assumption of residuals was found to be a better fit for price volatility of silver. Among the exogenous variables considered in this study, saving interest rate and general inflation rate have a statistically significant effect on monthly silver price volatility. In the EGARCH $(3,2)$ volatility model, the asymmetric term was found to be positive and significant. This is an indication that the unanticipated price increase had a greater impact on price volatility than the unanticipated price decrease in silver. Then, concerned stockholders such as portfolio managers, planners, bankers, and investors should intervene and pay due attention to these factors in the formulation of financial and related market policy.
\end{abstract}

\section{Introduction}

Silver is a natural precious metal that holds high economic value, either as a currency or as an industrial commodity [1]. Prices in precious metals such as silver have increased dramatically over the period from 1991 to 2011 . Such intense increases are due to several factors, such as inflation expectations, the recent economic crisis, and higher demand from emerging markets $[2,3]$. As a result, these intense changes in both markets have attracted investor attention since precious metals such as silver serve as important storehouses of value and play a role in risk diversification [4].

Price discovery is one of the key functions of futures markets, which provides a marketplace for industry participants and investors to manage commodity price risk.
Metal prices are volatile, reflecting the changing market's global nature. Volatility is one of the key aspects of financial markets, which is the range and speed of price movements showing the degree of variation in a trading price series over time as measured by the standard deviation of logarithmic returns $[5,6]$.

Currently, financial and commodity markets have been highly volatile, bringing risks and opportunities to traders and investors and should, therefore, be further examined. Appropriate processes for modeling volatility need to accurately capture the properties of financial time series. These properties have been identified as fat tails, sharp peaks, volatility clustering, and the correlation between lagged returns [7]. From an empirical point of view, the lagged correlation for any measure of volatility quantifies the 
volatility's memory shape and magnitude. The generalized autoregressive conditional heteroskedasticity (GARCH) presumes that the lagged correlations decay as an exponential. This implies that the memory in GARCH processes decay too fast and so not making use of all available information [8].

Statisticians and econometricians have developed various techniques for modeling volatility, such as the autoregressive conditional heteroskedasticity $(\mathrm{ARCH})$ model developed by Engle [9] and later generalized by Bollerslev [10]. Currently, ARCH models have rapidly grown into a rich family of empirical models for volatility forecasting over the past twenty years and are now widespread and essential tools in financial econometrics [11].

Several studies have been conducted to analyze the volatility of the price return of precious metals [12-16]. For instance, Ayele et al. [3] evaluated the key macroeconomic determinants of gold price volatility in the Ethiopian market and argued that macroeconomic factors, namely, interest rates, exchange rates, and crude oil prices, had a significant effect on gold price volatility. A study by Batten et al. [12] argued that gold price volatility is shown to be explained by monetary factors, but this is not true of silver. Overall, there is little evidence that the same macroeconomic factors jointly affect the volatility processes of the series of four precious metals (gold, silver, platinum, and palladium prices), while there is evidence of volatility feedback between the precious metals.

Volatility is a key player in the asset management game of the national economy and even for companies engaged in trading and fund management options; it is extremely important to precisely model and forecast the price volatility of precious metals $[17,18]$. Like other precious metals, silver is highly demanded as an investment in the photography industry, superconductor applications, and microcircuit markets and has been used as a source of money and store of value [19]. Owing to the smaller supply, lower market liquidity, and variations in demand between industrial and store value uses, the price of silver is extremely volatile compared with that of gold. This condition causes widemarket valuations, generating uncertainty [20]. People living in Ethiopia's visual culture had a strong cultural propensity to use the creation and use of artifacts made of gold and silver associated with ruling and religious elites commonly [21]. There are also common arts and crafts, such as textiles, basketry, necklaces, crosses, and jewelry, made from silver, in which Ethiopian people frequently used, especially in the Ethiopian Orthodox Church. However, as to the researchers' knowledge, there is no information (study) available in the dynamics of price volatility of silver in the Ethiopian market. This article was concerned with identifying the key macroeconomic factors that have a significant impact on silver price volatility and modeling and forecasting the silver price volatility dynamics in the Ethiopian market using GARCH family models.

Besides, understanding or examining volatility plays a central role in empirical finance and financial risk management and lies at the heart of any model for pricing derivative securities (commodity). Previous research works on changing volatility (conditional variance) using time series models have been active since the creation of the original ARCH model in 1982. From there, ARCH models grew rapidly into a rich family of empirical models for volatility forecasting during the last twenty years, and they are now widespread and essential tools in financial econometrics [11].

This paper incorporates the following elements in the scientific literature:

(1) From a statistical modeling point of view, this paper demonstrates the realistic application of the GARCH family model to financial risk management in a precious metal perspective

(2) The significant factors contributing to silver price volatility in Ethiopia are well known in this work, and this result is very useful to investors, researchers, and governmental and nongovernmental organizations for policy formulation and planning as a supporting tool for price volatility management in precious metal marketing

(3) Furthermore, the result of this study will be used as a basis for further study in this area, as well as for other commodity price volatilities

\section{Literature Review}

Ethiopia's reliance on a few export items for its foreignexchange agricultural products includes coffee, livestock products (leather, live animals, and meat), oilseeds and pulses, fruits, vegetables and flowers, textiles, natural gum, spices, and mineral products to some degree. Mineral resources may contribute to Ethiopia's economic growth, huge potential for minerals, and they will play a significant role in diversifying income. Precious metals are less used in the Ethiopian market by producing foreign exchange income to sustain the country's economy, and the need to leverage silver potential as an additional source of income is now highly triggered in Ethiopia. Silver's price swings between its perceived position as a store of wealth and its role as an industrial commodity, and silver market price fluctuations are more unpredictable than gold. Still, in Ethiopia, the price volatility of silver and its macroeconomic factors are less reported.

The academic literature has written extensively about price volatility in commodity markets. Many analysts have looked at volatility in commodity prices from different perspectives. A study by Solt and Swanson [22] found that the gold and silver futures market was weak in inefficient form and that investors could not gain abnormal profits. Also, another study by Ciner [23] analyzed the long-term trend in the prices of Tokyo Commodity Exchange-listed gold and silver futures contracts. Using cointegration analysis of the regular closing prices from 1992 to 1998 [24] (Johansen, 1991), the findings showed that the long-term stable relationship between future prices for gold and silver had vanished.

A study was conducted by Batten et al. [12] to model the monthly price volatility of four precious metals (gold, silver, 
platinum, and palladium) and to examine the macroeconomic determinants of these volatilities. They used the approximate conditional standard deviation (GARCH) model and the vector autoregressive (VAR) method to measure block exogeneity causality tests to conduct the empirical tests and to determine the volatility linkages between various macroeconomic variables and the precious metal market. It is shown that gold volatility is explained by monetary factors, but this is not true of silver. Generally, there is little evidence that the same macroeconomic factors form the volatility processes of the four precious metal price series together, although there is evidence of volatility input between the precious metals.

A study on the price volatility in the silver spot market provides some evidence that both good and bad news have no significant effect on silver price volatility. Both GARCH $(1,1)$ and EGARCH $(1,1)$ models were well fit for silver price volatility. The results also have implications for various agents that use silver. The volatility in the silver spot market could impact the futures market. Therefore, various agents that use silver should observe the futures markets to determine if hedging silver price volatility is an appropriate risk management tool [16].

Research was conducted by $\mathrm{Xu}$ and Fang [5] on the cross-linking of futures trading of precious metals between the U.S. and Japanese markets. They first compared the models with one lag, two lags, and three lags by using the Akaike information criterion (AIC) in estimating the bivariate GARCH model for gold, platinum, and silver. The two-lag model has the smallest AIC for all three precious metal futures; hence, it was selected as the correct model. The findings indicate that the transmission of prices is high and important in both markets. The terms for error correction, indicating long-term relationships between the U.S. and Japanese markets, are highly important, implying that both markets are moving forward in time. The results of the volatility analysis show that the GARCH $(2,2)$ model suits well with various spillover coefficients for all considered precious metals.

The role of financial factors in the gold market using a GJR-GARCH model is to examine the influence of the crude oil light sweet index, S\&P 500 stock index, the U.S. dollar/yen exchange rate, and the TNX 10-Year Treasury Note on the gold future price held by Kiohos and Sariannidis [25]. The empirical results show that a positive transmission effect from the leading energy market to the gold market is expressed in the first determinant, crude oil. The importance of these spillover effects largely represents the economic development of the world. On the contrary, not only because gold is a hedge against economic or political uncertainty but also because it provides alternate strategies in portfolio management, the S\&P 500 stock index, the US dollar/yen exchange rate, and the TNX 10Year Treasury Note hurt the gold market. Further research performed by Ayele et al. [3] in Ethiopia found that the best fit model was GARCH-M $(2,2)$ with Student's $t$-distribution for residuals. And macroeconomic factors also have a major effect on gold volatility, namely, interest rates, exchange rates, and crude oil prices.

\section{Data and Methodology}

3.1. Data Source. Secondary data on the monthly price of silver, exchange rate, saving interest rate, inflation rate, and price of crude oil were obtained from the National Bank of Ethiopia (NBE) over the period from January 1998 to January 2014.

3.2. Variables under the Study. The response variable in this study is the monthly price returns of silver in the Ethiopian market. The exogenous variables considered in this study are taken mostly based on earlier studies and economic theories $[1-3,26]$. The exogenous variables considered are those that are assumed to affect price volatility of precious metals which were exchange rate (of birr against the US dollar), general inflation rate (the rate at which the general level of prices for goods and services rises and falls) for both inflation rate of food items and the inflation rate of nonfood items, saving interest rate (the rate at which interest is paid by a borrower (the debtor) for the use of money for a lender (the creditor)), and price of crude oil (US dollar per barrel).

3.3. Empirical Methodology. In this study, the log-return series for the price of silver was considered since it gives a complete and scale-free summary of the series and return series are easier to handle and displays many of the typical facts in financial series such as leptokurtosis and volatility clustering [27-29]. In the literature, several procedures have been developed for testing stationarity of time series. In this study, the augmented Dickey-Fuller (ADF) test due to [30] and the Phillips-Perron (PP) test due to [31, 32] were considered for testing stationarity of the series.

3.4. Econometrics Model Specification. In this article, two distinct equations or specifications were employed: the first for the conditional mean and the second for the conditional variance (univariate extension of GARCH) employed to model monthly price volatility of silver in the Ethiopian market.

3.5. Autoregressive Moving Average (ARMA) Model. A stationary process $Y_{t}$ is called an $\operatorname{ARMA}(p, q)$ process, where $p$ and $q$ are integers, if there exist real coefficients $\alpha_{0}, \alpha_{1}, \ldots, \alpha_{p} ; \beta_{1}, \ldots, \beta_{q}$ such that

$$
Y_{t}=\mu+\sum_{i=1}^{p} \alpha_{i} Y_{t-i}+\varepsilon_{t}-\sum_{j=1}^{q} \beta_{j} \varepsilon_{t-j}, \quad \forall t \in Z,
$$

where $Y_{t}$ represents the current value of the series; $Y_{t-1}, Y_{t-2}, Y_{t-p}$ denote the past values of the same series; $\alpha_{1}, \alpha_{2}, \ldots, \alpha_{p}$ are the regression coefficients that show the effect of past values of the series on the current value of the series; $\beta_{1}, \beta_{2}, \ldots, \beta_{q}$ are the MA parameters (coefficients) which describe the effect of the past innovations on $Y_{t}$; and $\varepsilon_{t}$ is a white noise disturbance term, and it is independent of the past values of the response variable. We employed maximum likelihood (ML) methods to estimate the 
unknown parameter and tests related to serial correlation through Breusch-Godfrey LM, and the test of normality for residuals was performed using the Jarque-Bera test.

3.6. Autoregressive Conditional Heteroskedasticity (ARCH) Models. Autoregressive conditionally heteroskedasticity (ARCH) models were introduced by Engle [9], and they are specifically designed to model and forecast conditional variances. Let $\sigma_{t}^{2}$ denote the variance conditional on information at time $t-1$, and then, an $\mathrm{ARCH}(\mathrm{P})$ model by incorporating the explanatory variables is given by [33]

$$
\sigma_{t}^{2}=\alpha_{0}+\alpha_{1} \varepsilon_{t-1}^{2}+\alpha_{2} \varepsilon_{t-2}^{2}+\alpha_{3} \varepsilon_{t-3}^{2}+\cdots+\alpha_{p} \varepsilon_{t-p}^{2}+\mathbf{X}_{t}^{\prime} \boldsymbol{\phi},
$$

where $\varepsilon_{t-1}^{2}, \ldots, \varepsilon_{t-p}^{2}$ are the lagged squared residuals from the conditional mean equation with the nonnegativity restrictions $\alpha_{0}>0, \alpha_{i} \geq 0, i=1,2, \ldots, p, \mathbf{X}_{t}=\left(X_{1 t}, X_{2 t}, \ldots\right.$, $\left.X_{r t}\right)^{\prime}$ is a vector of explanatory variables at time $t$, $\phi=\left(\phi_{1}, \phi_{2}, \ldots, \phi_{r}\right)^{\prime}$ is a vector of regression coefficients that show the effect of the explanatory variables on the volatility of the price return series under consideration, $\alpha_{0}$ shows the long-term volatility, and $\alpha_{1}, \alpha_{2}, \ldots, \alpha_{p}$ indicate the effect of past shocks irrespective of their sign.

3.7. Generalized Autoregressive Conditional Heteroskedasticity (GARCH) Models. GARCH is an extension of an ARCH model of Engle [9] by Bollerslev [10]. GARCH is a mechanism that includes past variances in the explanation of future variances. The symmetric GARCH $(p, q)$ model with explanatory variables is given as

$$
\begin{aligned}
Y_{t} & =\mu+\varepsilon_{t}, \\
\varepsilon_{t} & =\sigma_{t} \eta_{t}, \\
\sigma_{t}^{2} & =\alpha_{0}+\sum_{i=1}^{p} \alpha_{i} \varepsilon_{t-i}^{2}+\sum_{j=1}^{q} \beta_{j} \sigma_{t-j}^{2}+\mathbf{X}_{t}^{\prime} \phi, t \varepsilon Z,
\end{aligned}
$$

where $\operatorname{var}\left(\varepsilon_{t} \mid \psi_{t-1}\right)=E\left(\varepsilon_{t}^{2} \mid \psi_{t-1}\right)=\sigma_{t}^{2}$ and $E\left(\varepsilon_{t} \mid \psi_{t-1}\right)=0$, $\alpha_{0}$ shows the long-term volatility, $\alpha_{1}, \alpha_{2}, \ldots, \alpha_{p}$ indicate the effect of past shocks, and $\beta_{1}, \beta_{2}, \ldots, \beta_{q}$ show the influence of past volatility on the current volatility. We impose the restrictions $\alpha_{0}>0, \alpha_{i} \geq 0$, and $\beta_{j} \geq 0$ for $i=1,2, \ldots, p$ and $j=1,2, \ldots, q$ to ensure that the conditional variance is nonnegative, and $\left(\sum_{i=1}^{p} \alpha_{i}+\sum_{j=1}^{q} \beta_{j}<1\right)$ is a necessary and sufficient condition for the stability of the conditional variance equation. The main drawback of symmetric GARCH models is that the conditional variance is unable to respond asymmetrically to rises and falls in $\varepsilon_{t}$, and the leverage effects observed in returns cannot be accounted for.

3.8. The Exponential GARCH (EGARCH) Model. This model captures asymmetric responses of the time-varying variance to shocks and, at the same time, ensures that the variance is always positive. An EGARCH $(p, q)$ variance equation with explanatory variables is given by [34] $\ln \left(\sigma_{t}^{2}\right)=\alpha_{0}+\sum_{i=1}^{p} \alpha_{i}\left\{\left|\frac{\varepsilon_{t-i}}{\sigma_{t-i}}\right|-\gamma_{i} \frac{\varepsilon_{t-i}}{\sigma_{t-i}}\right\}+\sum_{j=1}^{q} \beta_{j} \ln \left(\sigma_{t-j}^{2}\right)+\mathbf{X}_{t}^{\prime} \boldsymbol{\phi}$.

The parameter $\gamma_{i}$ thus signifies the leverage effect of $\varepsilon_{t-i}$. Bad news can have a larger impact on volatility; again, we expect $\gamma_{i}$ to be negative in real applications.

\subsection{Parameter Estimation and Model Selection of ARCH/} GARCH Models. To estimate the unknown parameters of the GARCH family models, the maximum likelihood (ML) method is employed with various distributional assumptions for the error terms. In this study, we applied Akaike's information criterion (AIC) and Bayesian information criteria (BIC) for the model selection purpose.

\section{Results and Discussion}

4.1. Descriptive Statistics. The data used in this study was the monthly price of silver (in birr per gram) in the Ethiopian market for the period from January 1998 through January 2014, and the logarithmic return series were computed from the monthly price series $p_{t}$ to examine the price volatility. As can be seen from Table 1, the monthly average price of silver was about $35.57 \mathrm{ETB}$ with a minimum price of $6.08 \mathrm{ETB}$ and a maximum price of 109.11 ETB. The return series display a negative skewness and kurtosis coefficient of about -0.293167 and 5.32604, respectively, meaning that the return series are highly leptokurtic. Similarly, the Jarque-Bera (JB) test also confirms that the null hypothesis of normality for the monthly return series should be rejected at $1 \%$ level of significance. The rejection of the hypothesis of normality silver return series might be due to the existence of excess kurtosis. The observed monthly silver price shows an increasing trend over the study period, and high volatility periods of absolute return series are observed for the series under consideration (Figure 1).

4.2. Unit Root Test for Nonstationarity. In this study, the augmented Dickey-Fuller test (ADF) and Phillips-Perron (PP) test are used to check stationarity of the monthly natural $\log$ return series of silver price and exogenous variables. As we can see from Table 2, the unit root null hypothesis would not be rejected in both ADF and PP tests for all exogenous variables. On the contrary, for the price return series of silver, the null hypothesis of unit root is rejected at $1 \%$ level of significance indicating that the price return series are stationary. Since both unit root tests reject stationarity of the explanatory variables in levels, we take the first differences of the series and test if the unit root problem is still present. As can be seen from Table 2, the null hypothesis of unit root is rejected at $1 \%$ level of significance for all explanatory variables by both $\mathrm{ADF}$ and PP tests. Thus, all explanatory variables are integrated of order one (I (1)).

4.3. Specification of the Conditional Mean Equation. To specify the conditional mean equation for the series, a 
TABle 1: Summary statistics for monthly prices of silver (price per gram in birr) and their return series.

\begin{tabular}{lcc}
\hline Statistic & Price & Return series \\
\hline Mean & 35.57731 & 0.011810 \\
Median & 29.13362 & 0.003608 \\
Maximum & 109.1157 & 0.385227 \\
Minimum & 6.086868 & -0.436659 \\
Std. dev. & 25.52546 & 0.112231 \\
Skewness & 1.209819 & $-\mathbf{0 . 2 9 3 1 6 7}$ \\
Kurtosis & 3.437361 & $\mathbf{5 . 3 2 6 0 4 9}$ \\
Jarque-Bera & 48.61935 & 46.03432 \\
Probability & 0.00000 & 0.00000 \\
Observations & 193 & 192 \\
\hline
\end{tabular}

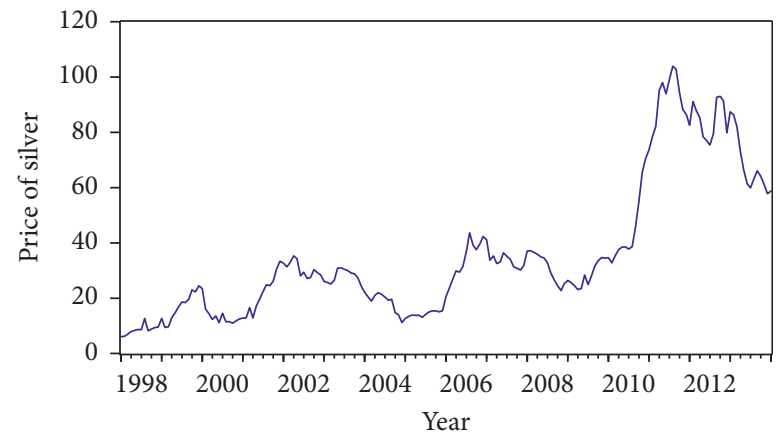

(a)

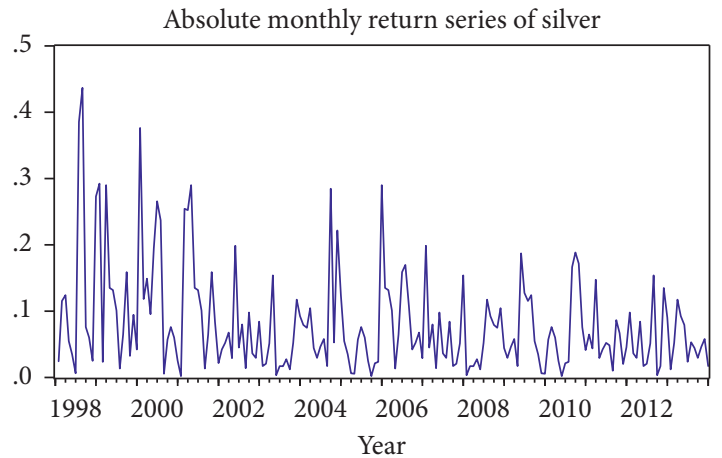

(b)

FIGURE 1: The price trend and absolute monthly return series of silver over the study period.

TABLE 2: The ADF and PP unit root tests at level and first differenced for the series.

\begin{tabular}{|c|c|c|c|c|c|c|}
\hline \multirow[b]{2}{*}{ Variables } & \multicolumn{2}{|c|}{ ADF test } & \multicolumn{2}{|c|}{ PP test } & \multicolumn{2}{|c|}{ First differenced } \\
\hline & $t$-Statistic & $P$ value & $t$-Statistic & $P$ value & $\begin{array}{l}\text { ADF test } \\
t \text {-Statistic }\end{array}$ & $\begin{array}{c}\text { PP test } \\
t \text {-Statistic }\end{array}$ \\
\hline Crude oil & -1.512 & 0.525 & -1.282 & 0.637 & $-9.426^{*}$ & $-9.408^{*}$ \\
\hline Exchange rate & 1.93213 & 0.999 & 1.7948 & 0.999 & $-12.019^{*}$ & $-12.019^{*}$ \\
\hline General inflation rate & 1.599841 & 0.999 & 2.1324 & 0.999 & $-5.121^{*}$ & $-8.648^{*}$ \\
\hline Inflation rate of food items & 0.66696 & 0.991 & 1.2221 & 0.998 & $-6.107^{*}$ & $-9.921^{*}$ \\
\hline Inflation rate of nonfood items & 2.218027 & 1.00 & 4.2888 & 1.000 & $-3.727^{*}$ & $-10.862^{*}$ \\
\hline Saving interest rate & -1.83399 & 0.363 & -1.837 & 0.361 & $-13.767^{*}$ & $-13.767^{*}$ \\
\hline Price return series of silver & -8.30578 & 0.000 & -13.99 & 0.000 & - & - \\
\hline
\end{tabular}

*Significant at $1 \%$ level of significance.

comparison of various $\operatorname{AR}(p), \operatorname{MA}(q)$, and $\operatorname{ARMA}(p, q)$ models was performed, and the one with the smallest information criteria was selected. By parsimonious principle, lower-order ARMA models were considered, and the fifteen combinations of AR (0-3) and MA (0-3) were considered. Among those, models with no serial correlation in the residuals were considered (Table 3 ). ARMA $(1,3)$ model was selected as the mean equation for the price return series of silver since it has the smallest AIC and SBIC. The presence of serial correlation in the residuals was tested using the Lagrange multiplier (LM) for the tentatively selected ARMA $(1,3)$ model for the conditional mean in the return series. The Breusch-Godfrey serial correlation LM test results in Table 4 provide evidence that there is no serial correlation in the residuals of the mean equation up to lag 3 . Moreover, the
Jarque-Bera statistic is not significant which indicates that the residuals of the tentatively fitted model are normally distributed the series under consideration (Table 4).

4.4. Test for ARCH Effects. One of the most important issues before applying the generalized autoregressive conditional heteroskedasticity (GARCH) model is to first examine the residuals of the price return series for evidence of heteroskedasticity. The results of the Lagrange multiplier (LM) test for $\mathrm{ARCH}$ effects in the squared residuals are shown in Table 5; the null hypothesis of no ARCH effect in the first three lags of residuals from the mean equations for monthly price return series was rejected. This implies that the conditional variance of the monthly price return series of silver 
TABLE 3: Parameter estimates of competing ARMA models with information criteria using MLE.

\begin{tabular}{lcccccc}
\hline Model & Parameter & Coefficients & Std. error & t-Statistic & $P$ value & $\begin{array}{c}\text { Information criteria } \\
\text { AIC }\end{array}$ \\
& & & & & -1.51618 \\
SBIC
\end{tabular}

TABLE 4: Test of serial correlation and normality for the residuals of the tentatively fitted ARMA $(1,3)$ model.

\begin{tabular}{lccc}
\hline Statistic & \multicolumn{3}{c}{ Lag } \\
& 1 & 2 & 3 \\
\hline F-statistic & 0.946195 & 0.476227 & 2.48187 \\
$\chi^{2}$ & $(0.331960)$ & $(0.62187)$ & $(0.06243)$ \\
statistic & 0.851700 & 0.8634 & 7.351168 \\
JB & $(0.356072)$ & $(0.649406)$ & $(0.06151)$ \\
statistic & & $2.447089(0.294)$ & \\
\hline
\end{tabular}

Note: values in parentheses are $P$ values.

is nonconstant. These results indicate that the respective return series under consideration have a nonconstant variance (heteroskedasticity) and need to be modeled using GARCH family models.

4.5. GARCH Family Models. Once the presence of ARCH effects is confirmed, then the optimal lag for GARCH family models has to be determined before the construction of the final model. Various symmetric (GARCH and GARCH-M) and asymmetric (EGARCH and TGARCH) models for silver price return series were considered. Low-order GARCH $(p, q)$ models are generally preferred to high-order $\mathrm{ARCH}$ $(p)$ for reasons of parsimony and better numerical stability of estimation [35]. GARCH $(2,0)$ and $\operatorname{GARCH}(3,3)$ models under the generalized error distributional (GED) assumption for residuals, $\operatorname{EGARCH}(3,2)$ model under the normal distributional assumption for residuals, and GARCH-M (1, $2)$, TGARCH $(0,1)$, and TGARCH $(3,3)$ models under the GED assumption for residuals were selected as candidate models for the price volatility of silver since they possess minimum AIC and SBIC. Moreover, to select the appropriate conditional volatility model, we consider the forecasting performance (RMSE, MAE, and MAPE) of the selected symmetric and asymmetric GARCH models (Table 6). ARMA $(1,3)$-EGARCH $(3,2)$ model with the normal distributional assumption for residuals performs better to describe price volatility of silver since it possesses the smallest forecast error measures in the majority of the statistics considered.
TABLE 5: ARCH effect test using LM test for squared residuals of the fitted models for conditional mean.

\begin{tabular}{lccc}
\hline & F-statistic & $\begin{array}{c}\text { Chi-squared statistic } \\
\left(\chi^{2}\right)\end{array}$ & SBIC \\
\hline $\begin{array}{l}\text { ARCH } \\
(1)\end{array}$ & 12.31028 & $11.67665(0.000633)$ & -4.50069 \\
ARCH & $(0.000564)$ & & \\
$(2)$ & 6.083447 & $11.60407(0.003021)$ & -4.46758 \\
ARCH & $(0.002759)$ & & \\
$(3)$ & 4.228577 & $12.12552(0.006965)$ & -4.43852 \\
\hline
\end{tabular}

Note: values in parentheses are $P$ values.

4.6. Parameter Estimation. The ARMA $(1,3)-\mathrm{EGARCH}$ (3, 2) model with the normal distributional assumption for residuals was selected as a better fit based on AIC and/or SBIC and forecast accuracy measures, and then the next step is to perform analysis of the determinants of monthly price volatility of silver. The parameters in the mean and variance equations are estimated using the maximum likelihood (ML) method as shown in Table 7.

The coefficient estimate of saving interest rate is statistically significant at 5\% level. Moreover, the coefficient estimate of the general inflation rate is statistically significant at $1 \%$ level. This indicates that saving interest rate and general inflation rate have a statistically significant effect on the current monthly price volatility of silver. This result was consistent with findings by $\mathrm{Xu}$ and Fang [5], which asserted that the price of silver is extremely volatile reacting to the interactions of global factors such as inflation, saving interest rate, and various economic and political events. On the contrary, this result is not in line with the findings of Batten et al. [12], which asserted that both monetary and financial variables show a nonsignificant effect on the price of silver. Among the explanatory variables which are considered in this study, the exchange rate and price of crude oil show a nonsignificant effect on the current monthly price volatility of silver.

The results also indicate that lagged shocks (i.e., $\mathrm{ARCH}$ $(-1)$, ARCH (-2), and ARCH (-3) terms) of the monthly price of silver have a statistically significant effect on the current monthly price volatility of silver. Similarly, EGARCH (-1) and EGARCH (-2) terms are statistically 
TABLE 6: Comparison of candidate models for the price volatility of silver using the forecasting accuracy measures.

\begin{tabular}{|c|c|c|c|c|}
\hline \multirow{2}{*}{ Candidate model } & \multirow{2}{*}{ Error distribution } & \multicolumn{3}{|c|}{ Forecasting accuracy measure } \\
\hline & & RMSE & MAE & MAPE \\
\hline GARCH-M $(1,2)$ & GED & 0.1181 & 0.0770 & 128.08 \\
\hline $\operatorname{GARCH}(2,0)$ & GED & 0.1157 & 0.0786 & 126.63 \\
\hline $\operatorname{GARCH}(3,3)$ & GED & 0.1142 & 0.0781 & 121.23 \\
\hline $\operatorname{EGARCH}(3,2)$ & Normal & 0.1122 & 0.0632 & 112.357 \\
\hline $\operatorname{TGARCH}(0,1)$ & GED & 0.115 & 0.077 & 118.99 \\
\hline $\operatorname{TGARCH}(3,3)$ & GED & 0.116 & 0.079 & 128.03 \\
\hline
\end{tabular}

RMSE: root mean squared error; MAE: mean absolute error; MAPE: mean absolute percent error.

TABLE 7: ML parameter estimates of the $\operatorname{ARMA}(1,3)$-EGARCH $(3,2)$ volatility model under the normal distributional assumption of the residual for price return series of silver.

\begin{tabular}{|c|c|c|c|c|c|}
\hline Parameter & Variables & Coefficients & Std. error & Statistic & $P$ value \\
\hline \multirow{5}{*}{ Mean equation } & Constant & -0.000686 & 0.005747 & -0.119411 & 0.9049 \\
\hline & $\mathrm{AR}(1)$ & -0.423396 & 0.195479 & -2.165938 & $0.0303^{* *}$ \\
\hline & $\operatorname{MA}(1)$ & 0.675648 & 0.154133 & 4.383531 & $0.0000^{*}$ \\
\hline & $\operatorname{MA}(2)$ & 0.374537 & 0.028299 & 13.23510 & $0.0000^{*}$ \\
\hline & $\operatorname{MA}(3)$ & 0.211123 & 0.031042 & 6.801143 & $0.0000^{*}$ \\
\hline \multirow{11}{*}{ Variance equation } & Constant & -13.35269 & 0.648682 & -20.58433 & $0.0000^{*}$ \\
\hline & $\operatorname{ARCH}(-1)$ & 1.021688 & 0.239459 & 4.266642 & $0.0000^{*}$ \\
\hline & $\mathrm{ARCH}(-2)$ & 0.959286 & 0.164583 & 5.828567 & $0.0000^{*}$ \\
\hline & $\operatorname{ARCH}(-3)$ & 1.205999 & 0.260989 & 4.620888 & $0.0000^{*}$ \\
\hline & Asymmetric $(-1)$ & 0.545054 & 0.182957 & 2.979136 & $0.0029^{*}$ \\
\hline & $\operatorname{EGARCH}(-1)$ & -0.432781 & 0.016068 & -26.93501 & $0.0000^{*}$ \\
\hline & EGARCH $(-2)$ & -0.878201 & 0.030126 & -29.15064 & $0.0000^{*}$ \\
\hline & General inflation rate & -0.774831 & 0.046881 & -16.52760 & $0.0000^{*}$ \\
\hline & Saving interest rate & -0.791274 & 0.298948 & -2.646862 & $0.0081^{*}$ \\
\hline & Exchange rate & 0.422090 & 0.225022 & 1.875771 & 0.0607 \\
\hline & Price of crude oil & 0.024219 & 0.013810 & 1.753759 & 0.0795 \\
\hline
\end{tabular}

Significant at ${ }^{*} 1 \%$ level and ${ }^{* *} 5 \%$ level.

significant at $1 \%$ level. These indicate that the current monthly price volatility of silver was affected by its 1 - and 2 month lagged price volatility. Additionally, the coefficient of the asymmetric term was positive and statistically significant at $1 \%$ level-an indication that bad news (unexpected increase in monthly price) had a larger impact on the price volatility of silver than good news (unexpected decrease in monthly price).

4.7. Checking the Adequacy of the Fitted Models. To check whether the fitted models are a good fit for the data or not, different diagnostic tests were performed. The Breusch-Godfrey serial correlation LM test indicates that the standardized residuals of the fitted model did not exhibit any additional ARCH effect (Table 8). Moreover, the Ljung-Box test for the squared standardized residuals of the fitted model also indicates insignificant $\mathrm{ARCH}$ effects (Figure 2). The Jarque-Bera test statistic was also insignificant (Figure 3), which indicates that the residuals of the fitted model were approximately normally distributed. Therefore, the selection of the ARMA $(1,3)$-EGARCH $(3,2)$ model with a normal error distributional assumption to investigate the determinants of the price volatility of silver
TABLE 8: ARCH-LM test for standardized residuals of the fitted volatility models.

\begin{tabular}{lcc}
\hline ARCH order & $\chi^{2}$ statistic & $F$-statistic \\
\hline ARCH $(1)$ & $0.056136(0.08127)$ & $0.055561(0.8139)$ \\
ARCH $(2)$ & $0.088513(0.9567)$ & $0.04357(0.9574)$ \\
ARCH(3) & $0.142597(0.9863)$ & $0.04655(0.9866)$ \\
\hline
\end{tabular}

Note: values in parentheses are $P$ values.

was well justified. In-sample forecasting using the ARMA (1, 3)-EGARCH $(3,2)$ volatility model was done. As can be seen from Figure 4, the high price volatility of silver was observed around the years 1998, 1999, and 2000. On the contrary, the low price volatility of silver was observed around the years 2001, 2005, and after 2008.

\section{Conclusions}

Due to the growing need to control and track exposure to asset price fluctuation, modeling volatility plays a rising role in the current unpredictable market environment in financial markets. Traders, portfolio managers, and investors are increasingly interested in understanding the price 
Correlogram of standardized residual squared

Date: $05 / 24 / 14$

Sample: 1998M 03 2014M01

Included observations: 191

Q-statistic probabilities adjusted for 4 ARMA term(s)

\begin{tabular}{|c|c|c|c|c|c|c|}
\hline Auto correlation & Partial correlation & & $\mathrm{AC}$ & PAC & Q-stat & Prob \\
\hline $\begin{array}{l}1 \\
1 \\
1 \\
1\end{array}$ & $\nabla$ & $\begin{array}{r}1 \\
2 \\
3 \\
4 \\
5 \\
6 \\
7 \\
8 \\
9 \\
10 \\
11 \\
12 \\
13 \\
14 \\
15 \\
16 \\
17 \\
18 \\
19 \\
20 \\
21 \\
22 \\
23 \\
24 \\
25 \\
26 \\
27 \\
28 \\
29 \\
30 \\
31 \\
32 \\
33 \\
34 \\
35 \\
36\end{array}$ & $\begin{array}{r}0.023 \\
-0.042 \\
-0.035 \\
0.005 \\
0.030 \\
0.091 \\
0.007 \\
0.101 \\
-0.034 \\
0.040 \\
-0.040 \\
0.001 \\
0.165 \\
0.031 \\
0.088 \\
-0.048 \\
0.062 \\
0.263 \\
-0.066 \\
-0.059 \\
0.037 \\
-0.005 \\
0.055 \\
-0.008 \\
0.025 \\
-0.016 \\
-0.012 \\
0.032 \\
-0.049 \\
-0.035 \\
0.155 \\
0.036 \\
-0.005 \\
-0.072 \\
-0.007 \\
-0.061\end{array}$ & $\begin{array}{r}0.023 \\
-0.043 \\
-0.034 \\
0.005 \\
0.027 \\
0.089 \\
0.006 \\
0.111 \\
-0.033 \\
0.051 \\
-0.045 \\
-0.004 \\
0.161 \\
0.002 \\
0.114 \\
-0.062 \\
0.097 \\
0.259 \\
-0.108 \\
-0.027 \\
0.000 \\
-0.001 \\
0.009 \\
-0.039 \\
-0.034 \\
-0.083 \\
0.015 \\
-0.016 \\
-0.040 \\
-0.057 \\
0.064 \\
0.050 \\
-0.052 \\
-0.015 \\
-0.040 \\
-0.152\end{array}$ & $\begin{array}{l}0.1005 \\
0.4441 \\
06905 \\
0.6963 \\
0.8698 \\
2.5105 \\
2.5203 \\
4.5698 \\
4.8106 \\
5.1335 \\
5.4640 \\
5.4643 \\
11.074 \\
11.272 \\
12.897 \\
13.376 \\
14.186 \\
28.902 \\
29.837 \\
30.587 \\
30.880 \\
30.885 \\
31.552 \\
31.566 \\
31.700 \\
31.761 \\
31.795 \\
32.028 \\
32.584 \\
32.860 \\
38.696 \\
38.697 \\
38.704 \\
39.908 \\
39.919 \\
40.795\end{array}$ & $\begin{array}{l}0.351 \\
0.285 \\
0.472 \\
0.334 \\
0.439 \\
0.527 \\
0.604 \\
0.707 \\
0.271 \\
0.337 \\
0.300 \\
0.342 \\
0.361 \\
0.011 \\
0.013 \\
0.015 \\
0.021 \\
0.030 \\
0.035 \\
0.048 \\
0.063 \\
0.082 \\
0.104 \\
0.126 \\
0.142 \\
0.166 \\
0.072 \\
0.086 \\
0.107 \\
0.107 \\
0.131 \\
0.137\end{array}$ \\
\hline
\end{tabular}

FIgURE 2: ARCH effect test using Ljung-Box test for squared residuals of the fitted volatility model for silver.

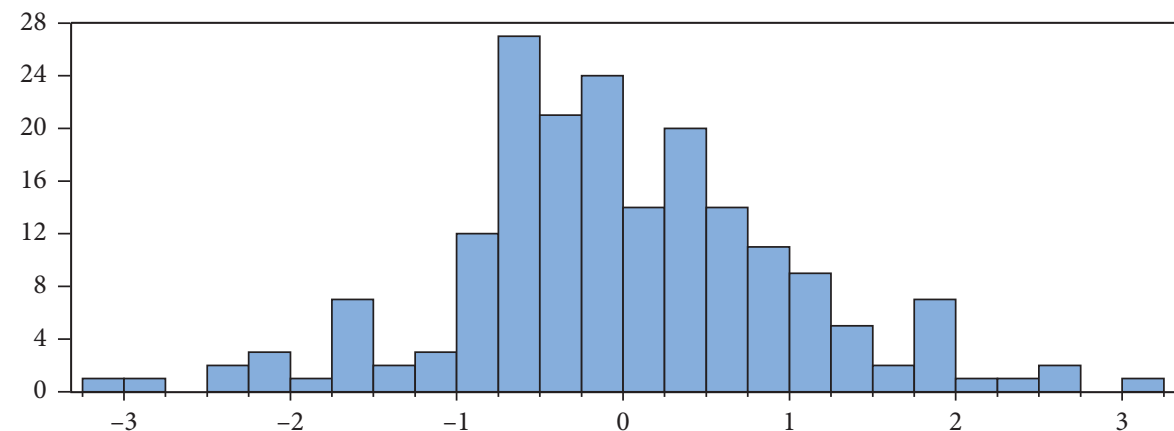

\begin{tabular}{|ll|}
\hline \multicolumn{2}{|l|}{$\begin{array}{l}\text { Series: standardized residuals } \\
\text { sample 1998M03 }\end{array}$ 2014M01 } \\
observations 191 & \\
Mean & 0.002185 \\
Median & -0.055173 \\
Maximum & 3.235548 \\
Minimum & -3.223021 \\
Std. dev. & 1.018724 \\
Skewness & 0.078173 \\
Kurtosis & 3.798241 \\
Jarque-Bera & 5.265490 \\
Probability & 0.071881 \\
\hline
\end{tabular}

Figure 3: Histogram of standardized residuals for the test of normality of residuals from the fitted model for price of silver series.

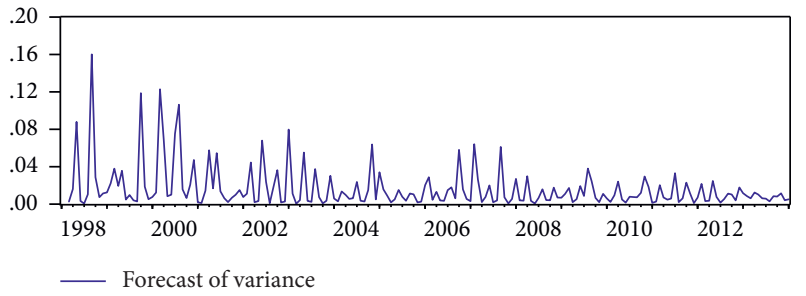

FIGURE 4: In-sample forecast of monthly price volatility of silver using the $\operatorname{EGARCH}(3,2)$ volatility model. volatility of valuable metals, especially gold, silver, and platinum, as they have been recognized as valuable metals and used as an investment tool. This work concerns to model and forecast the silver price volatility dynamics on the Ethiopian market using the GARCH family models over the study period.

The price of silver series shows an increasing pattern from the preliminary analysis over the period considered. Besides, the silver price return series shows the characteristics of financial time series such as leptokurtic 
distributions. This provides sufficient ground for the use of GARCH family models. Before going to the volatility model specification, we specify the conditional mean equation using ARMA models. ARMA $(1,3)$ was selected as the mean equation of the silver price return series using AIC and/or SBIC criteria. The ARCH-LM and Ljung-Box tests also support the presence of ARCH effects in the residuals of the conditional mean equations. Among the GARCH family models considered to model price volatility silver on the Ethiopian market, asymmetric $\operatorname{EGARCH}(3,2)$ model with the normal residual distribution assumption was found to be better suited to silver price volatility. In the $\operatorname{EGARCH}(3,2)$ volatility model for silver, the asymmetric term was found to be positive and significant. This is an indication that an unforeseen price increase had a greater impact on price volatility than an unforeseen decrease in silver prices. Among the macroeconomic variables considered, saving interest rate and general inflation rate have been found to have a statistically significant effect on silver's monthly price volatility. The price volatility forecast over the study period has shown us that silver prices fluctuate greatly.

This study recommends that careful control of the price of silver should be given attention as it shows volatility throughout the study period as it may affect the country's economy to some extent, and appropriate policy options should be planned to deal with silver price volatility as well as others. We also recommend concerned stockholders such as financial authorities, portfolio managers, planners, bankers, and investors in which they should intervene and pay due attention to the identified macroeconomic factors in the formulation of financial and related market policy. We also suggest the use of the econometrics methodology employed in this work by future researchers to investigate the market dynamics of various commodities and other precious metals in the Ethiopian economy. To evaluate the intertemporal relation and price dynamism impact between precious metals (gold, silver, and platinum) and common export commodities (coffee, livestock products, and oilseeds) on the Ethiopian market, further research is recommended.

\section{Abbreviations}

ADF: $\quad$ Augmented Dickey-Fuller test

AIC: $\quad$ Akaike information criteria

AR: Autoregressive

ARCH: Autoregressive conditional heteroskedastic

ARMA: Autoregressive moving average

EGARCH: Exponential generalized autoregressive conditional heteroskedastic

GARCH: Generalized autoregressive conditional heteroskedastic

GED: $\quad$ Generalized error distribution

LM: $\quad$ Lagrange multiplier

MA: $\quad$ Moving average

PP: $\quad$ Phillips and Perron test

SBIC: $\quad$ Schwarz Bayesian information criteria

TGARCH: Threshold generalized autoregressive conditional heteroskedastic.

\section{Data Availability}

All the datasets used and analyzed during the current study are available within the article.

\section{Conflicts of Interest}

The authors declare that they have no conflicts of interest.

\section{Acknowledgments}

The authors are thankful to the National Bank of Ethiopia (NBE).

\section{References}

[1] R. Sari, S. Hammoudeh, and U. Soytas, "Dynamics of oil price, precious metal prices, and exchange rate," Energy Economics, vol. 32, no. 2, pp. 351-362, 2010.

[2] W.-C. Lee and H.-N. Lin, "The dynamic relationship between gold and silver futures markets based on copula-AR-GJRGARCH model," Middle Eastern Finance and Economics, vol. 7, pp. 118-129, 2010.

[3] A. W. Ayele, E. Gabreyohannes, and Y. Y. Tesfay, "Macroeconomic determinants of volatility for the gold price in Ethiopia: the application of GARCH and EWMA volatility models," Global Business Review, vol. 18, no. 2, pp. 308-326, 2017.

[4] B. Adrangi, A. Chatrath, and K. Raffiee, "Economic activity, inflation, and hedging," The Journal of Wealth Management, vol. 6, no. 2, pp. 60-77, 2003.

[5] X. E. Xu and H.-G. Fung, "Cross-market linkages between U.S. and Japanese precious metals futures trading," Journal of International Financial Markets, Institutions and Money, vol. 15, no. 2, pp. 107-124, 2005.

[6] Y.-J. Zhang and Y.-M. Wei, "The crude oil market and the gold market: evidence for cointegration, causality and price discovery," Resources Policy, vol. 35, no. 3, pp. 168-177, 2010.

[7] S.-H. Poon, A Practical Guide to Forecasting Financial Market Volatility, John Wiley \& Sons, Hoboken, NY, USA, 2005.

[8] A. Gustafsson and P. Söderström, "Volatility Processes and VaR: A Study of Industry Standards and Potential Improvements," 2010, https://www.diva-portal.org/smash/ record.jsf?pid=diva2\%3A344958\&dswid=3715.

[9] R. F. Engle, "Autoregressive conditional heteroscedasticity with estimates of the variance of United Kingdom inflation," Econometrica, vol. 50, no. 4, pp. 987-1007, 1982.

[10] T. Bollerslev, "Generalized autoregressive conditional heteroskedasticity," Journal of Econometrics, vol. 31, no. 3, pp. 307-327, 1986.

[11] D. Ardia, Financial Risk Management with Bayesian Estimation of GARCH Models, Springer, Berlin, Germany, 2008.

[12] J. A. Batten, C. Ciner, and B. M. Lucey, "The macroeconomic determinants of volatility in precious metals markets," Resources Policy, vol. 35, no. 2, pp. 65-71, 2010.

[13] S. M. Hammoudeh, Y. Yuan, M. McAleer, and M. A. Thompson, "Precious metals-exchange rate volatility transmissions and hedging strategies," International Review of Economics \& Finance, vol. 19, no. 4, pp. 633-647, 2010.

[14] L. Morales and B. Andreosso-O'Callaghan, "Volatility analysis of precious metals returns and oil returns: an ICSS approach," Journal of Economics and Finance, vol. 38, no. 3, pp. 492-517, 2014. 
[15] A. A. A. Khalifa, H. Miao, and S. Ramchander, "Return distributions and volatility forecasting in metal futures markets: evidence from gold, silver, and copper," Journal of Futures Markets, vol. 31, no. 1, pp. 55-80, 2011.

[16] A. Harper, Z. Jin, R. Sokunle, and M. Wadhwa, "Price volatility in the silver spot market: an empirical study using Garch applications," Journal of Finance and Accountancy, vol. 13, p. 1, 2013.

[17] L. Morales, "Volatility spillovers on precious metals markets: the effects of the asian crisis," in Proceedings of the European Applied Business Research Conference (EABR), Salzburg, Austria, June 2008.

[18] S. A. Vigne, B. M. Lucey, F. A. O’Connor, and L. Yarovaya, "The financial economics of white precious metals-a survey," International Review of Financial Analysis, vol. 52, pp. 292308, 2017.

[19] P. Singh, "Evaluation of efficiency and effectiveness of silver as investment," International Journal of Latest Trends in Engineering and Technology, vol. 6, no. 1, 2015.

[20] B. M. Lucey and E. Tully, "Seasonality, risk and return in daily COMEX gold and silver data 1982-2002," Applied Financial Economics, vol. 16, no. 4, pp. 319-333, 2006.

[21] R. A. Silverman and N. W. Sonania, "Gold and silver at the crossroads in highland Ethiopia," International Journal of Ethiopian Studies, vol. 1, no. 2, pp. 82-109, 2004.

[22] M. E. Solt and P. J. Swanson, "On the efficiency of the markets for gold and silver," The Journal of Business, vol. 54, no. 3, pp. 453-478, 1981.

[23] C. Ciner, "On the long run relationship between gold and silver prices A note," Global Finance Journal, vol. 12, no. 2, pp. 299-303, 2001.

[24] S. Johansen, "Estimation and hypothesis testing of cointegration vectors in Gaussian vector autoregressive models," Econometrica, vol. 59, no. 6, pp. 1551-1580, 1991.

[25] A. Kiohos and N. Sariannidis, "Determinants of the asymmetric gold market," Investment Management and Financial Innovations, vol. 7, no. 4, pp. 26-33, 2010.

[26] W. Ensi, K. H. Al-Yahyaee, and S. H. Kang, "Time-varying volatility spillovers between stock and precious metal markets with portfolio implications," Resources Policy, vol. 53, pp. 88-102, 2017.

[27] D. Falk Soylu, "Dimension reduction methods for predicting financial data," UUDM. Project Report 2015:17, Uppsala University, Uppsala, Sweden, 2015.

[28] R. S. Tsay, Analysis of Financial Time Series, vol. 543, JohnWiley \& Sons, Hoboken, NY, USA, 2005.

[29] E. Foscolo, "Analysis of financial time series with eviews," 2012, http://www.pawsthecatcafe.com/analysis_of_financial_ time_series_with_eviews.pdf.

[30] D. A. Dickey and W. A. Fuller, "Distribution of the estimators for autoregressive time series with a unit root," Journal of the American Statistical Association, vol. 74, no. 366a, pp. 427431, 1979.

[31] P. Perron and P. C. Phillips, Does GNP have a Unit Root?: A Reevaluation, Université de Montréal, Département de Science économique et Centre de, Montreal, Canada, 1986.

[32] P. C. B. Phillips and P. Perron, "Testing for a unit root in time series regression,” Biometrika, vol. 75, no. 2, pp. 335-346, 1988.

[33] D. B. Nelson, "Conditional heteroskedasticity in asset returns: a new approach," Econometrica, vol. 59, no. 2, pp. 347-370, 1991.
[34] H. Malmsten, "Evaluating exponential GARCH models," Stockholm School of Economics, Stockholm, Sweden, SSE/ EFI Working Paper Series in Economics and Finance, 2004.

[35] T. G. Andersen, Handbook of Financial Time Series, Springer Science \& Business Media, Berlin, Germany, 2009. 